\title{
Effect of Educational Program About Self-care Practices on Preventing Occurrence of Vaginal Infection Among Gestational Diabetic Women
}

\author{
Nawal K. Abd Elkhalek ${ }^{1}$ \& Sahar F. Elsayed ${ }^{2}$. \\ ${ }^{1 .}$ Lecturer of Obstetrics and Gynecological Nursing, Faculty of Nursing, South Valley University, Egypt. \\ 2. Assistant Professor of Obstetrics and Gynecological Nursing, Faculty of Nursing, South Valley University, Egypt.
}

\begin{abstract}
Background: gestational diabetic women are reported to be high risk for infections of the genital tract. Controlling vaginal infections rested on the nurse through educating women self-care practices. Aim: To assess the effect of educational program about self-care practices on prevention occurrence of vaginal infection among gestational diabetic women. Methods: Quasi experimental research design was used in this study. It was conducted at antenatal outpatient clinic of South Valley University's Hospital. Sample included 60 pregnant women with diabetes mellitus. Structured interview and self-care model was used and involved three parts. An educational program about care of genital system was carried out on pregnant women with gestational diabetes. Results: There is statistical significant difference between control and study groups regarding total self-care practices and occurrence of genital infection Pvalues are 0.001. Conclusion: There was a vital role to the educational program about self-care practices on preventing occurrence of vaginal infection among pregnant women. Recommendations: Planning and implementing educational program as a routine hospital care with providing a brochure about genital hygienic practices are important to reduce rate of vaginal infection among gestational diabetes women.
\end{abstract}

\section{Keywords: Educational Program, Vaginal Infection \& Gestational Diabetic Women.}

\section{Introduction}

Diabetes mellitus continue to affect growing numbers of women in their childbearing years and increasing their risk of obstetric complications (Chu et al., 2017). Gestational diabetes mellitus (GDM) is a type of diabetes diagnosed during the 2 nd or 3 rd trimester of pregnancy and is clearly not overt diabetes (American Diabetes Association, 2018).

It is "widely accepted" that the incidence of infections is greater in diabetes mellitus patients. Increased recurrence of cervicovaginal infections is associated with a multitude of factors regarding the elevated glucose concentrations in the vaginal mucosa (Lukic et al., 2017) Nowakowska et al. reported that the risk of vaginal Candida colonization in pregnant women is more than four times higher in women with DM compared to non-diabetic women, also postulating an elevated risk in those with GDM (Nowakowska et al., 2015)

For screening and diagnosis of GDM, the International Association of Diabetes and Pregnancy Study Groups (IADPSG) recently in 2015, issued new criteria. According to the IADPSG recommendations, fasting plasma glucose should be measured in the first prenatal visit and women with fasting blood glucose (FBG) $>7.0 \mathrm{mmol} / \mathrm{L}$ will be diagnosed with overt $\mathrm{DM}$ and those with $\mathrm{FBG}>5.1 \mathrm{mmol} / \mathrm{L}$ will be diagnosed with GDM. For women with FBG $<5.1 \mathrm{mmol} / \mathrm{L}$, a $75-\mathrm{g}$ 2-hour oral glucose tolerance test (OGTT) should be performed at 24 to 28 weeks (Pettker et al., 2017). GDM is associated with increased risk of maternal complications such as spontaneous preterm birth, premature rupture of membrane (PROM), chorioamnionitis, traumatic complications of vaginal delivery, cesarean delivery, morbidity from operative delivery, preeclampsia, and risk of developing metabolic syndrome or DM (Sacks et al., 2015) \& (Varner et al., 2017). GDM is also associated with poor metabolic control, higher body mass index, and impaired leukocyte function, some studies have suggested that GDM is associated with disturbances in the vaginal flora and vagina infections, but this is controversial. Infections caused by Candida are relatively well known to be associated with GDM, but much less is known about bacterial infections (Marschalek et al., 2016).

When managing vaginal infections the nurse takes the responsibility to modify the practices and to improve and prevent recurrence of vaginal infections. The prevention requires changing in self-care practices that put the women under the risk of infection, and the women should be taught about the most common symptoms and risk factors for vaginal infections (Baraia et al, 2016)

Self- care practices refer to activities and attitudes, which add to the upkeep of prosperity and personal 
wellbeing and advance human improvement. As far as health maintenance, self-care is any action as a person with the expectation of enhancing or reestablishing wellbeing, or treating or anticipating sickness. Vaginal infection related self-care themes include: personal hygiene, perineal hygiene, sexual hygiene, and menstrual hygiene (Baraia et al., 2017).

The notion that self-care is a major mainstay of health, and social consideration implies it is a vital part of a modern human services framework administered by bureaucracy and legislation. Concern has been raised by world health organization (WHO, 2015).

About whether vaginal, sexual or menstrual selfpractices could have harmful effects such as increasing the susceptibility to sexually transmitted infection (STI) or reproductive tract infection (RTI). They recommend that more evidence is needed to confirm a correlation between an increased risk of RTI and Gestational diabetes and vaginal practices, but they are modifiable through health education and prevention messages by the maternity nurses (WHO, 2015).

Vulvovaginal conditions are treated on an outpatient basis, unless the patient has other medical problems, and women may express embarrassment, guilt, or anger and may be concerned that the infection may be serious (causing infertility) or that it may have been acquired from a sex partner. In these points patient teaching, tact, and reassurance are important aspects of nursing care (Abdelnaem, et al., 2019).

\section{Significance of the study}

Vulvovaginitis is common among diabetic patients. Patients with diabetes, especially those with poorly controlled glycaemia, are risk to have genital mycotic infections. The main cause of vulvovaginal infections in diabetic women is $\mathrm{C}$. albicans. Genetics, pregnancy, estrogen have been identified as the main risk factors for vaginitis in diabetic patients (Kalra \& Kalra, 2017).

DM increased risk for infection as it associated with reduced response of neutrophil function, $T$ cells, and disorders of humoral immunity (Tinelli, 2018) Also a study performed to compare occurrence of vaginal infections in gestational diabetic women, and found that vulvovaginal candidiasis was higher in gestational diabetic women compared with healthy pregnant women (22.6\% vs 9.7\%; P < 0.001) (La Vignera et al., 2019) Pregnant women with diabetes have a high risk of Candida infection because the elevated sugar level in the blood provides food for yeast and encourages Candida overgrowth (Sopian et al., 2016) Also Nowakowska et al. 2015 reported that risk of vaginal infection in pregnant women is more than four times higher in women with DM compared to non-diabetic women.
Also Epidemiological studies have reported that pregnant women exposed to bacterial and fungal infections are at higher risk of maternal and neonatal complications (Lukic et al., 2017), so the researcher interested to identify effect of educational program on prevention occurrence of vaginal infection among pregnant women with gestational diabetes.

\section{Aim of the study}

This study aimed to

Assess the effect of educational program about self-care practices on preventing occurrence of vaginal infection among gestational diabetic women.

\section{Research hypothesis:}

Women who attended an educational program about self-care practices on preventing occurrence of vaginal infection exhibits less vaginal infection than those who don't attend.

\section{Patients \& Methods}

Patients and methods were showed into four designs technical, operational, administrative, and statistical design.

\section{Technical Design}

Which included research design, setting, sample and tools of data collection.

\section{Research Design:}

A quasi-experimental (control and study) design was used in this study.

\section{Setting}

The study was implemented at antenatal outpatient clinics of South Valley University’s Hospital, Qena governorate. It serves Qena governorate only. Antenatal outpatient clinics included two rooms, one for interviewing the pregnant women and taking history that have a sector for physical examination and the other room for ultrasound examination.

\section{Sample}

A total of 60 pregnant women with gestational diabetes involved in the study that divided into two equal groups control (30 pregnant women received routine hospital care) and study (30 pregnant women received educational program about selfcare practices). The sample calculated using the following equation.

Sample size $n=[\operatorname{DEFF} * \mathbf{N p}(\mathbf{1}-\mathbf{p})] /\left[\left(\mathbf{d}^{2} / \mathbf{Z}^{2}{ }_{1}\right.\right.$. $a / 2 *(\mathbf{N}-1)+p *(1-p)]$

DEFF $($ Design effect $)=1$

$\mathrm{N}($ population $)=120$

$\mathrm{p}($ Hypothesized $\%)=10 \%+/-5$

$\mathrm{d}$ (tolerated margin of error) $=0.05$

$\mathrm{Z}$ (level of confidence $)=1.96$

$\alpha$ (Alpha) $=0.05$

$\mathrm{n}=[1 * 120 * 10 \%+/-5 \quad(1-10 \%+/-5) / \quad[(0.05) 2 /$

(1.96) $21-0.05 *(120-1)+10 \%+/-5(1-10 \%+/-5)]$

$\mathrm{n}=60$ pregnant women with gestational diabetes

Inclusion criteria

- Pregnant woman diagnosed with gestational diabetes 
- Between 24-28 weeks' gestation

- No presence of vaginal infection

- Single fetus

Tools of the study

A structured interview questionnaire was designed by the researchers and included three parts.

Part one: included personal data of gestational diabetic women as (age, education, occupation, and residence). Part two: involved obstetrics data (previous and current) as gravidity, parity, abortion, stillbirth, previous pregnancy complications, mode of previous delivery, and weeks of gestation. Part three: Self-care model included 15 items (practical actions designed by Infectious Diseases Society of America) directed to pregnant women with gestational diabetes to assess their implementation or not as precautions to prevent vaginal infection (Pappas et al., 2015).

\section{Practice scoring system}

Each practice was scored as (1) for done action and (0) for not done action. While the total practices score was calculated as the following: $<70 \%$ was unsatisfactory and if $70 \%$ and more was satisfactory.

\section{Supportive materials}

It was prepared by the researcher based on literature review. It planned in a form of brochure with using a simple and clear Arabic language that contained practices regarding genital care supported with photo to act as a guide for them at home and support their information.

\section{Tools validity and reliability}

The face and content validity of the study tools was assessed by a jury consisted of experts in the maternity and gynecological nursing department of faculty of nursing, South Valley University for comprehensiveness, accuracy, and clarity in language. Study tools were tested for its internal consistency by Cronbach's Alpha. It was 0.810 for the questionnaire.

\section{Operational design}

It was presented in two phases pilot study and field work.

\section{Pilot study}

Pilot study was involved (10\%) according to inclusion of the sample size (6 cases) of pregnant women with gestational diabetes to evaluate clarity and efficiency of the study's tool.

\section{Field work}

Data collection took about ten months started from the beginning of May 2019, and completed by the end March 2020. It was implemented in three phases, pre intervention, intervention and post intervention:

Phase 1 (Pre intervention phase) for the control and the study groups

The researcher attended at South Valley University (antenatal outpatient clinics) three days per week from $9 \mathrm{am}$ to $1 \mathrm{pm}$. The researcher interviewed with each pregnant woman diagnosed with gestational diabetes individually, introduced herself then explained the aim of the study and ensures their cooperation. Then oral consent from participants was obtained. The researcher chose an envelope to determine the group that the pregnant woman (control or study). The researcher started to fill the structure interview questionnaire from the pregnant woman to assess personal characteristics, and current and past obstetric data. It took about 20 to 25 minutes.

\section{Phase 1 (Intervention phase)}

\section{A) For the control group}

The pregnant woman received routine antenatal hospital care during her pregnancy till labor.

\section{B) For the study group}

The researcher met with all pregnant gestational diabetic women involved in the study group in each day at the end of the day in a separate room (studying room that found beside outpatient clinic). The women's number in each educational session ranged from $1-2$ pregnant women. The total number of groups was 18 groups. The researcher explained to pregnant women practices regarding methods to care for genital areas, and precautions that they should be done to prevent occurrence of vaginal infection that involved general practices as Cut nails frequently, perineal hygiene as use daily perineal pad and sexual hygiene as genital care before and after intercourse. This implemented in a lecture form supported by pictures and videos that took a time from 40-60 minutes. The researcher gave pregnant woman the content of lecture in a brochure to be a guide to her till labor.

Phase 3: Post intervention phase (follow up) for the control and the study groups:

After one week of first meeting with pregnant women. The researcher ask the pregnant women about actions or precautions and checked if done or not and fill the third part of the tool based on her talk. Then the researcher followed up pregnant women with gestational diabetes every two weeks through telephone till labor to identify appearance of any sings \& symptoms of vaginal infection and if any, the pregnant woman asked to come to the outpatient clinics and genital infection ensured after diagnosed by obstetrician.

\section{Administrative design}

This study was carried out under the approval of faculty of nursing's Ethical committee, South Valley University, also an official permission was obtained from the director of South Valley University Hospital, informed consent was taken from each woman involved in the study, confidentiality was assured. The woman was freely to withdraw from the study at any stage.

\section{Statistical design}

The collected data were organized, categorized, coded, tabulated and analyzed using the Statistical Package for social sciences (SPSS). Data were presented and tables and charts using numbers, 
percentages, means, and standard deviation. Correlation between variables (Pearson correlation) and chi-square test was used statistical significance was considered at $\mathrm{P}$-value $\leq 0.05$.

\section{Results}

Table (1): Distribution of studied pregnant women according to personal data in control and study groups $(\mathbb{N}=\mathbf{3 0}$ for each group).

\begin{tabular}{|c|c|c|c|c|c|}
\hline \multirow[t]{2}{*}{ Personal data } & \multicolumn{2}{|c|}{$\begin{array}{c}\text { Control group } \\
(30)\end{array}$} & \multicolumn{2}{|c|}{$\begin{array}{c}\text { Study group } \\
(30)\end{array}$} & \multirow[t]{2}{*}{ P-value } \\
\hline & No & $\%$ & No & $\%$ & \\
\hline \multicolumn{6}{|l|}{$\overline{\text { Age group }}$} \\
\hline Less than 25 year & 6 & 20.0 & 9 & 30.0 & \multirow{3}{*}{0.061} \\
\hline 25 - less than 35 year & 19 & 63.3 & 14 & 46.7 & \\
\hline 35 year or more & 5 & 16.7 & 7 & 23.3 & \\
\hline Mean \pm SD(range/years) & \multicolumn{2}{|c|}{$26.23 \pm 4.23(21-39)$} & \multicolumn{2}{|c|}{$28.56 \pm 5.41(20-38)$} & \\
\hline \multicolumn{6}{|l|}{ level of education } \\
\hline Illiterate and Read and write & 8 & 26.7 & 9 & 30.0 & \multirow{4}{*}{0.445} \\
\hline Basic education & 6 & 20.0 & 4 & 13.3 & \\
\hline Secondary & 10 & 33.3 & 9 & 30.0 & \\
\hline University & 6 & 20.0 & 8 & 26.7 & \\
\hline \multicolumn{6}{|l|}{ Occupation } \\
\hline Employed & 12 & 40.0 & 10 & 33.3 & \multirow[b]{2}{*}{0.326} \\
\hline House wife & 18 & 60.0 & 20 & 66.7 & \\
\hline \multicolumn{6}{|l|}{ Address } \\
\hline Urban & 21 & 70.0 & 18 & 60.0 & \multirow[b]{2}{*}{0.138} \\
\hline Rural & 9 & 30.0 & 12 & 40.0 & \\
\hline \multicolumn{6}{|l|}{ Family history of DM } \\
\hline Yes & 21 & 70.0 & 23 & 76.7 & \multirow{3}{*}{0.285} \\
\hline No & 9 & 30.0 & 7 & 23.3 & \\
\hline Total & 30 & 100.0 & 30 & 100.0 & \\
\hline
\end{tabular}

Table (2): Distribution of studied pregnant women according to obstetric history in control and study groups $(\mathrm{N}=60 \longrightarrow 30$ for each group).

\begin{tabular}{|c|c|c|c|c|c|}
\hline \multirow[t]{2}{*}{ Obstetric history } & \multicolumn{2}{|c|}{$\begin{array}{c}\text { Control group } \\
\text { (30) }\end{array}$} & \multicolumn{2}{|c|}{$\begin{array}{c}\text { Study group } \\
(\mathbf{3 0})\end{array}$} & \multirow[t]{2}{*}{ P-value } \\
\hline & No & $\%$ & No & $\%$ & \\
\hline \multicolumn{6}{|l|}{ Gravidity } \\
\hline Primigravida & 8 & 26.7 & 11 & 36.7 & \multirow[b]{2}{*}{0.129} \\
\hline Multigravida & 22 & 73.3 & 19 & 63.3 & \\
\hline \multicolumn{6}{|l|}{ Parity } \\
\hline Nulliparaous & 10 & 33.3 & 12 & 40.0 & \multirow{3}{*}{0.350} \\
\hline Primipara & 5 & 16.7 & 4 & 13.3 & \\
\hline Multipara & 15 & 50.0 & 14 & 46.7 & \\
\hline \multicolumn{6}{|l|}{ Abortion } \\
\hline Yes & 7 & 23.3 & 8 & 26.7 & \multirow[b]{2}{*}{0.579} \\
\hline No & 23 & 76.7 & 22 & 73.3 & \\
\hline \multicolumn{6}{|l|}{ Still birth } \\
\hline Yes & 1 & 3.3 & 2 & 6.7 & \multirow[b]{2}{*}{0.271} \\
\hline No & 29 & 96.7 & 28 & 93.3 & \\
\hline Total & 30 & 100.0 & 30 & 100.0 & \\
\hline \multicolumn{5}{|l|}{ Previous pregnancy } & \multirow{3}{*}{0.767} \\
\hline Normal & 4 & 18.2 & 3 & 15.8 & \\
\hline Complicated & 19 & 81.8 & 16 & 84.2 & \\
\hline Total & 22 & 100.0 & 19 & 100.0 & \multirow[b]{4}{*}{0.280} \\
\hline \multicolumn{5}{|l|}{ The previous labor } & \\
\hline Normal & 5 & 25.0 & 6 & 33.3 & \\
\hline $\begin{array}{l}\text { Complicated as fetal distress or } \\
\text { obstructed labor }\end{array}$ & 15 & 75.0 & 12 & 66.7 & \\
\hline Total & 20 & 100.0 & 18 & 100.0 & \\
\hline
\end{tabular}


Table (3): Distribution of studied pregnant women according to current obstetric data in control and study groups $(\mathrm{N}=60$ 30 for each group).

\begin{tabular}{|c|c|c|c|c|c|}
\hline \multirow[t]{2}{*}{ Current obstetric data } & \multicolumn{2}{|c|}{$\begin{array}{c}\text { Control group } \\
(\mathbf{3 0})\end{array}$} & \multicolumn{2}{|c|}{$\begin{array}{l}\text { Study group } \\
(30)\end{array}$} & \multirow[t]{2}{*}{ P-value } \\
\hline & No & $\%$ & No & $\%$ & \\
\hline \multicolumn{6}{|c|}{$\begin{array}{l}\text { Weeks of gestation at time of included to the } \\
\text { study }\end{array}$} \\
\hline 24 - less than 26 weeks & 7 & 23.3 & 9 & 30.0 & \multirow{2}{*}{0.285} \\
\hline 26-28 weeks & 23 & 76.7 & 21 & 70.0 & \\
\hline \multicolumn{6}{|c|}{ Complications occurred through pregnancy } \\
\hline Yes & 25 & 83.3 & 19 & 63.3 & \multirow{2}{*}{$0.001 * *$} \\
\hline No & 5 & 16.7 & 11 & 36.7 & \\
\hline Total & 30 & 100.0 & 30 & 100.0 & \\
\hline \multicolumn{6}{|l|}{ Type of complication } \\
\hline Macrosomic fetus & 4 & 16.0 & 6 & 31.6 & \multirow{6}{*}{$0.019 * *$} \\
\hline Hypertention & 5 & 20.0 & 2 & 10.5 & \\
\hline PROM & 2 & 8.0 & 3 & 15.8 & \\
\hline Polyhydrominos & 4 & 16.0 & 3 & 15.8 & \\
\hline Preterm labor & 4 & 16.0 & 2 & 10.5 & \\
\hline Mix problem & 6 & 24.0 & 3 & 15.8 & \\
\hline Total & 25 & 100.0 & 19 & 100.0 & \\
\hline
\end{tabular}

(**) Highly statistical significant difference $P<0.01$

Table (4): Self-care practices among gestational diabetes women in control and study group.

\begin{tabular}{|c|c|c|c|c|c|c|c|c|c|}
\hline \multirow{3}{*}{ Genital care practices } & \multicolumn{4}{|c|}{$\begin{array}{c}\text { Control group } \\
\text { (30) }\end{array}$} & \multicolumn{4}{|c|}{$\begin{array}{l}\text { Study group } \\
(\mathbf{3 0})\end{array}$} & \multirow[t]{3}{*}{ P. value } \\
\hline & \multicolumn{2}{|c|}{ Done } & \multicolumn{2}{|c|}{ Not done } & \multicolumn{2}{|c|}{ Done } & \multicolumn{2}{|c|}{ Not done } & \\
\hline & No & $\%$ & No & $\%$ & No & $\%$ & No & $\%$ & \\
\hline \multicolumn{10}{|l|}{ General practices } \\
\hline Cut nails frequently & 15 & 50.0 & 15 & 50.0 & 28 & 93.3 & 2 & 6.7 & $0.001 * *$ \\
\hline Use public water cycle & 13 & 43.3 & 17 & 56.7 & 25 & 83.3 & 5 & 16.7 & $0.020 *$ \\
\hline $\begin{array}{l}\text { Washing hands before and after using } \\
\text { the toilet }\end{array}$ & 17 & 56.7 & 13 & 43.3 & 30 & 100.0 & 0 & 0.0 & $0.001 * *$ \\
\hline Drying after using toilet & 8 & 26.7 & 22 & 73.3 & 28 & 93.3 & 2 & 6.7 & $0.001 * *$ \\
\hline \multicolumn{10}{|l|}{ Perineal hygiene } \\
\hline External washing of the genital area & 24 & 80.0 & 6 & 20.0 & 30 & 100.0 & 0 & 0.0 & $0.002 * *$ \\
\hline Cleaning genital area with hands & 18 & 60.0 & 12 & 40.0 & 29 & 96.7 & 1 & 3.3 & $0.001 * *$ \\
\hline $\begin{array}{l}\text { Direction of cleaning the genital area } \\
\text { from front to back }\end{array}$ & 6 & 20.0 & 24 & 80.0 & 27 & 90.0 & 3 & 10.0 & $0.001 * *$ \\
\hline Use daily perineal pad & 5 & 16.7 & 25 & 83.3 & 27 & 90.0 & 3 & 10.0 & $0.001 * *$ \\
\hline Changing underwear daily & 9 & 30.0 & 21 & 70.0 & 28 & 93.3 & 2 & 6.7 & $0.001 * *$ \\
\hline Use cotton underwear & 12 & 40.0 & 18 & 60.0 & 26 & 86.7 & 4 & 13.3 & $0.001 * *$ \\
\hline Boil under wear and pads & 3 & 10.0 & 27 & 90.0 & 29 & 96.7 & 1 & 3.3 & $0.001 * *$ \\
\hline Hang under wear in sun rays & 13 & 43.3 & 17 & 56.7 & 30 & 100.0 & 0 & 0.0 & $0.001 * *$ \\
\hline \multicolumn{10}{|l|}{ Sexual hygiene } \\
\hline Genital care before and after intercourse & 6 & 20.0 & 24 & 80.0 & 30 & 100.0 & 0 & 0.0 & $0.001 * *$ \\
\hline
\end{tabular}

(**) Highly statistical significant difference $P<0.01$ 


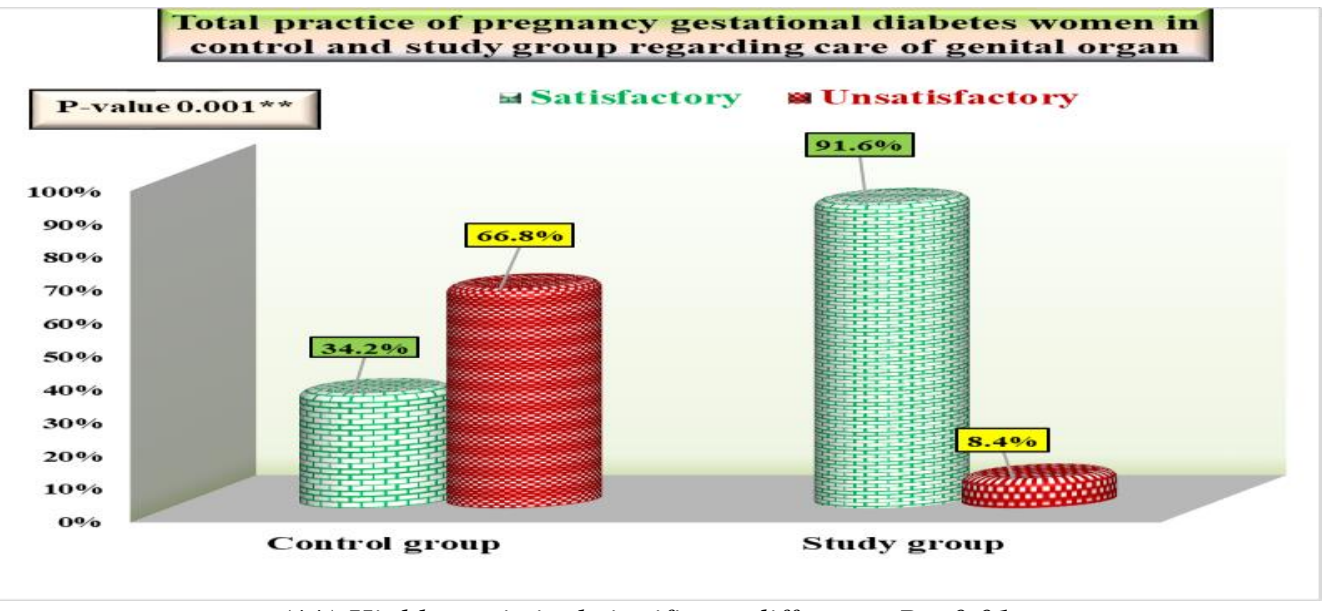

(**) Highly statistical significant difference $P<0.01$

Figure (1): Total self-care practices of pregnancy gestational diabetes women in control and study group regarding care of genital organ:

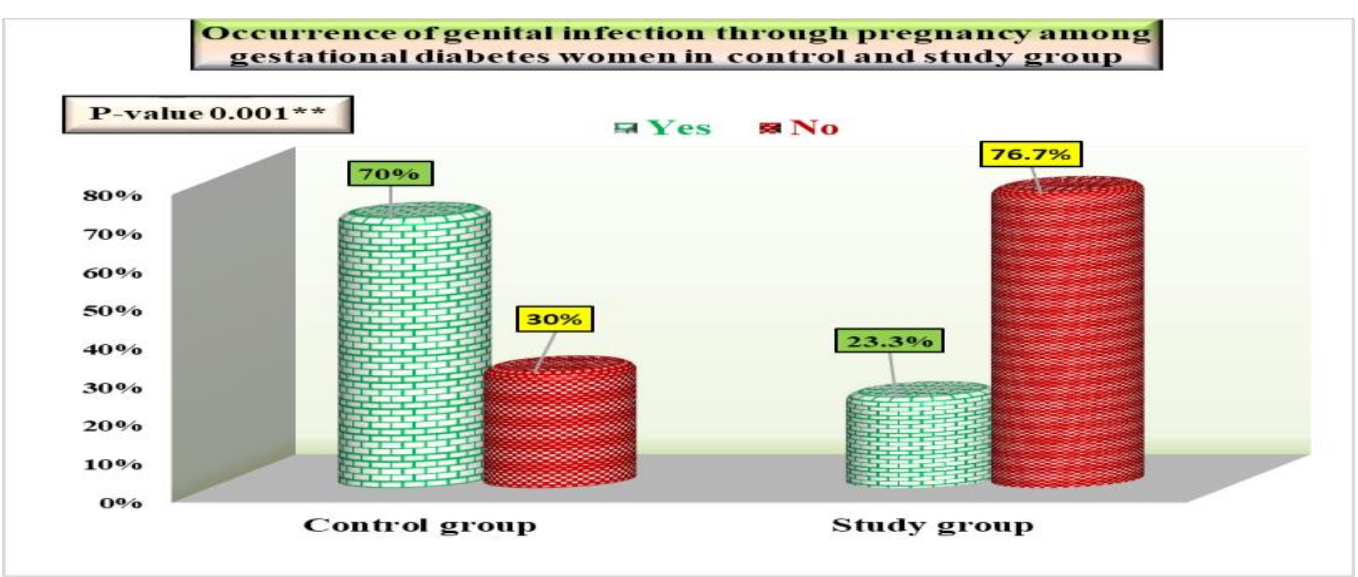

(**) Highly statistical significant difference $\mathrm{P}<0.01$

Figure (2): Occurrence of genital infection through pregnancy among gestational diabetes women in control and study group.

Table (5): Relationship between total practices of pregnancy gestational diabetes women and personal data:

\begin{tabular}{|c|c|c|c|c|c|c|}
\hline \multirow{3}{*}{ Personal data } & \multicolumn{4}{|c|}{ Total practices } & \multirow{3}{*}{$\begin{array}{c}\text { Total } \\
\mathbf{N}(\%)\end{array}$} & \multirow{3}{*}{ P-value } \\
\hline & \multicolumn{2}{|c|}{ Satisfactory (38) } & \multicolumn{2}{|c|}{ Unsatisfactory (22) } & & \\
\hline & No & $\%$ & No & $\%$ & & \\
\hline \multicolumn{7}{|l|}{ Age group } \\
\hline Less than 25 year & 10 & 66.7 & 5 & 33.3 & $15(100.0)$ & \multirow{3}{*}{ 0.033* } \\
\hline 25 - less than 53 year & 19 & 57.6 & 14 & 42.4 & $33(100.0)$ & \\
\hline 35 year or more & 9 & 75.0 & 3 & 25.0 & $12(100.0)$ & \\
\hline \multicolumn{7}{|l|}{ level of education } \\
\hline Illiterate and Read and write & 6 & 35.3 & 11 & 64.7 & $17(100.0)$ & \multirow{4}{*}{$0.001 * *$} \\
\hline Basic education & 6 & 60.0 & 4 & 40.0 & $10(100.0)$ & \\
\hline Secondary & 14 & 73.7 & 5 & 26.3 & $19(100.0)$ & \\
\hline University & 12 & 85.7 & 2 & 14.3 & $14(100.0)$ & \\
\hline \multicolumn{7}{|l|}{ Occupation } \\
\hline Employed & 15 & 68.2 & 7 & 31.8 & $22(100.0)$ & \multirow[t]{2}{*}{0.256} \\
\hline House wife & 23 & 60.5 & 15 & 39.5 & $38(100.0)$ & \\
\hline \multicolumn{7}{|l|}{ Address } \\
\hline Urban & 31 & 79.5 & 8 & 20.5 & $39(100.0)$ & \multirow[b]{2}{*}{ 0.001** } \\
\hline Rural & 7 & 33.3 & 14 & 66.7 & $21(100.0)$ & \\
\hline Total & 38 & 100.0 & 22 & 100.0 & $60(100.0)$ & \\
\hline
\end{tabular}

(**) Highly statistical significant difference $P<0.01$

(*) Statistical significant difference $P<0.05$ 
Table (6): Relationship between total self-care practices of pregnancy gestational diabetes women and occurrence of genital infection:

\begin{tabular}{|c|c|c|c|c|c|c|}
\hline & \multicolumn{4}{|c|}{ Total practices } & \multirow{3}{*}{$\begin{array}{c}\text { Total } \\
\mathbf{N}(\%)\end{array}$} & \multirow{3}{*}{ P-value } \\
\hline & \multicolumn{2}{|c|}{ Satisfactory (38) } & \multicolumn{2}{|c|}{ Unsatisfactory (22) } & & \\
\hline & No & $\%$ & No & $\%$ & & \\
\hline \multicolumn{7}{|c|}{ Occurrence of genital infection } \\
\hline Yes & 9 & 32.1 & 19 & 67.9 & $28(100.0)$ & \multirow[b]{2}{*}{$0.001 * *$} \\
\hline No & 29 & 90.6 & 3 & 9.4 & $32(100.0)$ & \\
\hline Total & 38 & 100.0 & 22 & 100.0 & $60(100.0)$ & \\
\hline
\end{tabular}

Table (1): Demonstrates personal data of pregnant women with gestational diabetes in control and study group and reports that $63.3 \%$ of studied pregnant women in control group and $46.7 \%$ in study group have an age group between $25-<35$ years with a mean \pm SD of $26.23 \pm 4.23$ and $28.56 \pm 5.41$ respectively, about $33.3 \%$ of them in control group and $30 \%$ in study group have a secondary level of education. Regarding occupation $60 \%$ in control group and $66.7 \%$ in study group are housewives, $70 \%$ and $60 \%$ in control and study group respectively lived in urban areas, about $70 \%$ of them in control group and $76.7 \%$ in study group have a family history of DM, with no statistical significant between control and study groups.

Table (2): Illustrates obstetric history of pregnant women with gestational diabetes in control and study group and shows that $73.3 \%$ \& $50 \%$ of them in control group and $63.3 \%$ \& 46.7 in study group are multigravida and multipara respectively. About $23.3 \% \& 3.3 \%$ in control group and $26.7 \%$ \&6.7 in study group have a history of abortion and still birth respectively, $81.8 \% \& 75.0 \%$ in control group and $84.2 \%$ \& 66.7 in study group have a history of complications in previous pregnancy and labor respectively, with no statistical significant difference between control and study groups.

Table (3): Clarifies current obstetric data of gestational diabetic women in control and study group and finds that $76.7 \%, 83.3 \%$ \& $24 \%$ of them in control group and $70 \%, 63.3 \% \& 15.8 \%$ in study group have a weeks of gestation from 26-28, have complications during their pregnancy, and have a mix problem during current pregnancy, with statistical significant difference between both groups regarding current problem and type of problem, $\mathrm{P}$ - values are 0.001 and 0.019 respectively.

Table (4): Reveals self-care practices among gestational diabetic women in control and study group and illustrates that there is statistical significant difference between both groups regarding general, perineal and sexual care practices.

Figure (1): Demonstrates that there is statistical significant difference between control and study groups regarding total practices of genital care $\mathrm{P}$ values is 0.001 .
Figure (2): Shows that there is statistical significant difference between control and study groups regarding occurrence of genital infection Pvalues is 0.001 .

Table (5): Reveals that there is relation between total self-care practices and age groups, educational level, and living areas, $\mathrm{p}$-value are $0.033,0.001$ and 0.001 respectively. And there is no relation between total self-care practices and occupation P-values is 0.256 .

Table (6): Displays that there is relation between total self-care practices and occurrence of genital infection among gestational diabetic women $\mathrm{P}$ values is 0.001 .

\section{Discussion}

It is reported that at least $75 \%$ of women have a history of genital infection worldwide. Incorrect self-care practices of women and deteroration in physiological characteristics of sensitive female genital organs increase the risk of exposure to infection (Sahin et al., 2016).

Concerning total self-care practices of diabetic pregnant woman (who involved in the study), current study reports that more than one third and the great majority of studied women have a satisfactory self-care practices in control and study group respectively with statistical significant difference between both groups, p- value 0.001 .

On the same line (Kaplan \& Peksoy, 2020) who applied their study in Turkey to identify the effect of training program based on information motivation behavioral (IMB) skills to women regarding genital infection practices, and found that only one third of studied women in control group and the majority of them in experimental group had a proper hygienic practices, with statistical significant difference between both groups, p- value 0.001. This reflects the need of pregnant women to be supported by educational and training programs to enhance their performance regarding self-care practices.

As regard self-care practices items, present study shows that there was statistical difference between control and study group regarding general, perineal and sexual hygienic practices.

Similar to previous study (Baraia et al., 2017) who implemented their study in Ismailia City, Egypt to assess the effect of self-care practices program for 
women diagnosed with vaginitis on their response to the protocol of management, and reported that there is statistical difference between control and study group regarding general, perineal, menstrual and sexual hygienic practices $\mathrm{p}$ - value 0.001 for all. Also (Hamed, 2015) who carried out their study in Egypt to identify the effect of genital hygienic practices on the occurrence of vaginal infection, and revealed that there was statistical difference between control and case group regarding general, menstrual and coital hygienic practices.

And (Nofal et al., 2020) who conducted their study at Zagazig City, Egypt to evaluate effect of prevention program on knowledge and practices regarding prevention of urinary tract infection among female adolescents, and illustrated that there was significant improvement in performing hygienic practices after implementation of program regarding care pf genital area p- value 0.001 .

On the other hand, (Kaplan \& Peksoy, 2020), demonstrated that there was no significant difference between pre and posttest regarding changing a sanitary pad during menstruation as a menstrual hygienic practice $\mathrm{p}$ value 0.070 , clean perineal area from front to back and exposed underwear to sun light as a perineal hygienic practices $p$ value 0.625 and 0.250 respectively. This difference may be back to dissimilarity in the selecting design and the chosen sample as well as the women characteristics.

Regarding occurrence of genital infection through pregnancy among studied women, actual study clarifies that more than two thirds in control group and more than one fifth in study group have genital tract infection through pregnancy with statistical significant difference between control and study group $\mathrm{p}$ value 0.001 .

Concurrent with previous results (Hamaad et al., 2019) who implemented their study in Riyadh, Saudi Arabia to identify the prevalence of vaginal infection in diabetic pregnant women and normal pregnant women, and showed that diabetic pregnant women had a higher percent of vaginal infection than normal pregnant women with statistical significant difference between them.

Also (Nelson et al., 2013) who applied their study in Kenya to assess prevalence of vaginal candidiasis and occurrence of Candida species in pregnant women attending the antenatal clinic, and found that there was statistical significant difference in the occurrence of vaginal candidiasis in pregnant women. This show the importance of educational program on self-care practices and its importance in reducing the occurrence of vaginal infections

When referring to relationship between total selfcare practices and personal data, existing study shows that there is relationship between total selfcare practices and age, education, and residence $\mathrm{p}$ value are $0.033,0.001$, and 0.001 respectively, but there is no relationship between total self-care practices and occupation p- value is 0.256 .

Agreed with previous results (Özlem et al., 2019), who applied their study in Ankara to assess genital hygienic behaviors of married women and the counseling provided to them, and reported that there was relation between genital hygienic behaviors and age and education level p- value were 0.006 and 0.025 respectively.

In congruent with previous results (Prasanthi et al., 2017), who carried out their study in Sri Lanka to assess knowledge and experience of childbearing women and lived in estate communities regarding vaginal discharge, and represented that there was no relation between genital hygienic practices and age and education level p- value were 0.664 and 0.546 respectively. This dis agreement back to difference in personal characteristics and setting between both studies.

Concerning relationship between total self-care practices and occurrence of genital infection among gestational diabetic women, present study demonstrates that there is relationship between total self-care practices and occurrence of genital infection p- value is 0.001 .

On the same line, (Baraia et al., 2017) \& (Nofal et al., 2020) who reported that women who followed self-care practices had a higher cure percent than other not follow it, which indicates the importance of self-care practices in improving and recurrent vaginal infection.Regarding personal and obstetric data of studied women, current study finds that there is no statistical significant difference between control and study group regarding age, education, occupation, residence, gravidity parity and abortion.

(Kaplan \& Peksoy, 2020) agreed with previous results, and showed that no statistical significant difference between control and experimental group regarding age, education and occupation.

Conclusion: There was a vital role to the educational program about self-care practices on preventing occurrence of vaginal infection among gestational diabetic women.

\section{Recommendations}

- Planning and implementing educational program as a routine hospital care about genital hygienic practices must be done to avoid harmful behaviors and reducing the rate of vaginal infection.

- Training programs should be conducted for nurses to train them in counseling women about the genital hygienic practices.

- A brochure about vaginal infection and hygienic self-care practices should be disseminated to pregnant women.

- Encourage early screening and treatment of vaginal infection. 
- Further studies and more interventions must be explored to improve women health and avoid genital tract infection

\section{Acknowledgement}

The researchers would like to express their thanks to all pregnant women who included in the study.

\section{References}

- Abdelnaem S., Ali, Hamido, S., \& Mohamed, H., (2019): Effect of self-care guidelines on knowledge and quality of life among faculty of nursing students with vaginal infection. Obstetrics \& Gynecology International Journal, 10(1). https://doi.org/10.15406/ogij.2019.10.00408

- American Diabetes Association (2018): Classification and diagnosis of diabetes: standards of medical care in diabetes. Diabetes Care 2018; 41(Supp.): S13-27.

- Baraia, Z., Abdallah, I., \& Nour, S., (2017): Impact of Educational Program about Self-care Practices on the Reliving of Vaginal Infection among High Risk Women in Ismailia City. IOSR Journal of Nursing and Health Science, 06(03), 73-78. https://doi.org/10.9790/1959-0603077378

- Baraia Z., Shalaby \& H., Imam (2016): Health Behaviors for Vaginal Infection among Married Women in Ismailia City, master diss, Suez Canal University.

- Chu S., Calla Ghan W., Kim S., SChmid C., lau J., England L., \& Dietz P., (2017): Maternal obesity and risk of gestational diabetes mellitus. Diabetes Care; 30: 20702076

- Pettker E., \& Zuckerwise L., (2017): Screening for gestational diabetes mellitus: are the criteria proposed by the international association of the Diabetes and Pregnancy Study Groups cost-effective? Diabetes Care, 35:529-35

- Hamaad, W., Alenizi, A., \& El-tahtawi, N., (2019): Prevalence of Vaginal Infections among Diabetic and NonDiabetic Saudi Pregnant Women. 48-53.

- Hamed, A., (2015): The Impact of Genital Hygiene Practices on the Occurrence of Vaginal Infection and the Development of a Nursing Fact Sheet as Prevention Massage for Vulnrable Women. 4(6), 55-64. https://doi.org/10.9790/1959-04655564

- Kalra B., \& Kalra S., (2017): Vulvovaginitis and diabe- tes. Journal of the Pakistan Medical Association 67(1): 143145.

- Kaplan, S., \& Peksoy, S., (2020): Assessment of the effectiveness of genital infection awareness training provided to women based on the IMB model. March. https://doi.org/10.4103/njcp.njcp
- La Vignera, S., Condorelli, R. Cannarella, R., Giacone, F., Mongioi', L., Cimino, L., Defeudis, G., Mazzilli, R., \& Calogero, A., (2019): Urogenital infections in patients with diabetes mellitus: Beyond the conventional aspects. International Journal of Immunopathology and Pharmacology, 33, 1-6. https://doi.org/10.1177/2058738419866582

- Lukic, A., Napoli, A., Santino, I., Bianchi, P., Nobili, F., Ciampittiello, G., Nardone, M., Santomauro, M., Di Properzio, M., \& Caserta, D., (2017): Cervicovaginal bacteria and fungi in pregnant diabetic and non-diabetic women a multicenter observational cohort. European Review for Medical and Pharmacological Sciences, 21(10), 2303-2315.

- Marschalek, J., Farr, A., Kiss, H., Hagmann, M., Göbl, C., Trofaier, M., Kueronya, V., \& Petricevic, L., (2016): Risk of vaginal infections at early gestation in patients with diabetic conditions during pregnancy: A retrospective cohort study. /Journal.Pone.0155182, 11(5), 1-10. https://doi.org/10.1371/journal.pone.0155182

- Nowakowska, D., Kurnatowska, A., Stray-Pedersen, B., \& Wilczynski, J., (2015): Prevalence of fungi in the vagina, rectum and oral cavity in pregnant diabetic women: Relation to gestational age and symptoms. Acta Obstetricia et Gynecologica Scandinavica, 83(3), 251$256 . \quad$ https://doi.org/10.1111/j.00016349.2004.0361.x

- Nelson, M., Wanjiru, W., \& Margaret, M., (2013): Prevalence of Vaginal Candidiasis and Determination of the Occurrence of Candida Species in Pregnant Women Attending the Antenatal Clinic of Thika District Hospital, Kenya. January. https://doi.org/10.4236/ojmm.2013.34040

- Nofal, A., Hammad, N., Abdallah, A., Magdy, H., \& Microbiology, M., (2020): Impact of Educational Program on The Level of Knowledge and Self-Care Behaviors towards Genitourinary Tract Infection among Female Adolescent Students In Zagazig City. 38(3), 86-93.

- Özlem, S., Çamözü, E., \& Tosun, B. (2019): Genital Hygiene Behaviors Among Married Women and the Outcomes of Counseling Practices. Hemşirelikte Araştırma Geliştirme Derneği-HEMAR-G Yayın Organıdır, 21(1-2), 12-22.

- Pappas, P., Kauffman, C., Andes, D., Clancy, C., Marr, K., Ostrosky-Zeichner, L., Reboli, A., Schuster, M., Vazquez, J., Walsh, T., Zaoutis, T., \& Sobel, J., (2015): Clinical Practice Guideline for the 
Management of Candidiasis: 2016 Update by the Infectious Diseases Society of America. Clinical Infectious Diseases, 62(4), e1-e50. https://doi.org/10.1093/cid/civ 933

- Prasanthi, M., Ilankoon, S., Sampatha, C., Goonewardena, E., Fernandopulle, R., Pradeep, P., \& Perera, R., (2017): Women's Knowledge and Experience of Abnormal Vaginal Women on the Other Side of War and Poverty: Its Effect Discharge Living in Estates in Colombo District, Sri on the Health of Reproduction Lanka. Aras Part Medical International Press, 5(2), 90-96. https://doi.org/10.15296/ijwhr.2017.17

- Sacks D., Black M., \& Li X., (2015): Adverse pregnancy outcomes using the international association of the diabetes and pregnancy study groups criteria: glycemic thresholds and associated risks. Obstet Gynecol, 126:67-73

- Sahin S., Özdemir K., Unsal A., Aygin D., \& Nemut T., (2016): An evaluation of the relationship between genital hygiene practices. Genital infection. Gynecol Obstet; 3:187.

- Sopian, I., Adam, M., Than, L., Thian, L., \& Doblin, S., (2016): Yeast Infection and Diabetes Mellitus among Pregnant Mother in Malaysia. Malays J Med Sci., 23(6), 2734.

- Tinelli, A., (2018): Vaginal infections in diabetic woman. January. https://doi.org/10.1285/i25327518v2i1p51

- Varner M., Rice M., \& Landon M., (2017): Pregnancies after the diagnosis of mild gestational diabetes mellitus and risk of cardiometa- bolic disorders. Obstet Gynecol, 129:273-80.

- World Health Organization (2015): A multi-country study on gender, sexuality and vaginal practices: Implications for sexual health. Department of Reproductive Health and Research 